
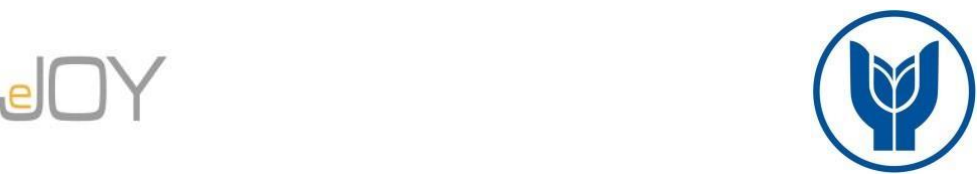

Şahin Kutlu, Ş. / Journal of Yasar University, 2021, 16/64, 1808-1822

\title{
Türkiye Ekonomisinde Sağlığa Dayalı Büyüme Hipotezinin Geçerliliğine İlişkin Ampirik Bir Analiz
}

\section{An Empirical Analysis of the Validity of Health-Led Growth Hypothesis in the Turkish Economy}

\author{
Şeyma ŞAHIN KUTLU, Bandırma Onyedi Eylül Üniversitesi, Türkiye, ssahin@ bandirma.edu.tr \\ Orcid No: 0000-0002-1485- 642X
}

\begin{abstract}
Öz: Sağllk harcamalarının ekonomik büyüme üzerindeki pozitif etkisi literatürde sağllğa dayalı büyüme hipotezi ile açıklanmaktadır. Bu hipoteze göre, artan sağlık harcamaları toplam faktör verimliliğini artırarak ekonomik büyümeyi teşvik etmektedir. Türkiye ekonomisinde sağlıkta dönüşüm programının uygulanmaya başladiğı 2003 yılından itibaren hem toplam sağlık harcamalarında hem de ekonomik büyüme hızında önemli artışlar yaşanmıştır. Bu birlikte artış ĕ̆ilimi, Türkiye ekonomisinde să̆lı̆̆a dayalı büyüme hipotezinin geçerliliğinin araştırılması için önem arz etmektedir. Bu çalışmada Türkiye ekonomisinde să̆lı̆̆a dayalı büyüme hipotezinin geçerliliği 19902019 dönemi için ampirik olarak incelenmiştir. Ampirik analiz yöntemi olarak ARDL sınır testi yaklaşımı kullanılmıştır. Çalışmada kişi başına düşen gelir üzerinde etkisi araştırılan değişkenler, kişi başına düşen sağlık harcamalarl, yükseköğretim brüt okullaşma oranı, doğrudan yabancı yatırımlar ve hanehalkı nihai tüketim harcamalarıdır. Çalışmanın sonuçları, kişi başına düşen sağlık harcamaları, doğrudan yabancı yatırımlar ve hanehalkı nihai tüketim harcamalarının kişi başına düşen gelir üzerinde uzun dönemde pozitif etkiye sahip olduğunu göstermektedir. Ancak yüksekögretim brüt okullaşma oranın kişi başına düşen gelir üzerindeki etkisi negatif olarak bulunmuştur. Kısa dönemde ise, kişi başına düşen să̆lık harcamalarl, yükseköğretim brüt okullaşma oranı ve hanehalkı nihai tüketim harcamaları kişi başına düşen gelir üzerinde pozitif bir etkiye sahiptir. Aynı zamanda, doğrudan yabancı yatırımların kişi başına düşen gelir üzerinde negatif bir etkiye sahip olduğu sonucuna ulaşılmıştır.
\end{abstract}

\section{Anahtar Kelimeler: Türkiye Ekonomisi, ARDL, Să̆lı̆̆a Dayalı Büyüme Hipotezi}

\section{JEL Sinıflandırmasl: H51, I15, C22}

\begin{abstract}
The positive effect of health expenditures on economic growth is explained by the health-led growth hypothesis in the literature. According to this hypothesis, increasing health expenditures increases economic growth by increasing total factor productivity. Since 2003, when the health transformation program was implemented in the Turkish economy, there have been significant increases in both the total health expenditures and the economic growth rate. This increase is important to investigate the health-led growth hypothesis in the Turkish economy. In this study, the health-led growth hypothesis in the Turkish economy was examined empirically for the period 1990-2019. ARDL bound test analysis is preferred as the method of empirical analysis. In the study, the variables that investigated the effects on per capita income are the per capita health expenditures, higher education gross enrollment rate, foreign direct investments, and household final consumption expenditures. The results of the analysis indicate that per capita health expenditures foreign direct investments and household final consumption expenditures have a positive effect on per capita income in the long run. However, the effect of higher education enrollment rate on per capita income is negative. In the short run, per capita, health expenditures, higher education gross enrollment rate, and household final consumption expenditures have a positive effect on per capita income. In addition, foreign direct investments have a negative effect on per capita income.
\end{abstract}

Keywords: Turkish Economy, ARDL, Health-Led Growth Hypothesis

JEL Classification: H51, I15, C22

\section{Giriş}

Romer (1986, 1990) ve Lucas (1988)'ın öncü çalışmalarından sonra ortaya çıan içsel büyüme modelleri, beşeri sermayenin ekonomik büyüme üzerindeki önemine vurgu yapmaktadır. Nitekim bilgi ve beceri stoğu olarak ifade edilebilen beşeri sermaye, üretim fonksiyonunun 
önemli bir bileşeni olarak tanımlanmaktadır (Kaya, vd., 2020: 139). Beşeri sermayeye katkıda bulunan en önemli unsurlardan biri ise sağlık göstergelerindeki iyileşmedir. Sağlık bir bütün olarak insan refahı için önemli olmakla birlikte üretkenliğin ve ekonomik büyümenin artırılması için önemli bir unsur olarak görülmektedir (Maduka vd., 2016). Analitik olarak toplumun sağlık düzeyinin iyileşmesi toplam faktör verimliliğinin artmasına katkı sağlayarak bireylerin daha üretken olmasını ve daha yüksek kazanç sağlamasını desteklemektedir. Ayrıca sağlık durumundaki iyileşme ortalama yaşam beklentisini artırarak toplumun daha uzun süre çalışmasına katkı sağlamaktadır. Dolayısıyla genel olarak toplumun sağlık durumu beşeri sermayenin verimliliğini artırarak uzun dönem büyümeyi teşvik etmektedir (Schultz, 1999: 69). Bununla birlikte sağlık durumu sağlı hizmetlerine yapılan harcamalar ile iyileşmektedir. Bahsedilen örüntü ile ekonomik büyüme üzerine pozitif yönlü etkisi ele alınan sağlık harcamalarındaki artış, bu yönüyle sağlığa dayalı büyüme hipotezinin konusunu oluşturmaktadır. (Mushkin, 1962: 129).

Bu hipotez doğrultusunda, sağlık bir sermaye olarak değerlendirilmekte ve sağlığa yapılan yatırımlar, beşeri ve fiziksel sermaye birikimi üzerindeki etkisi yoluyla ekonomik büyüme üzerinde pozitif etkilere sahip olmaktadır (Elmi ve Sadeghi, 2012: 88). Bunun aksine, sağlık durumunun zayıf olması toplam faktör verimliliğini azaltarak ekonomik büyüme üzerinde olumsuz bir etki oluşturmaktadır. Bu nedenle söz konusu durum dünyanın pek çok bölgesinde azgelişmişliğin açıklanmasında önemli bir faktör olarak görülmektedir (Cole ve Neumayer, 2006). Nitekim Sahra Altı Afrika ekonomilerindeki olumsuz sağlık koşullarının yoksulluk tuzağına sebep olduğu raporlanmıştır (Bloom ve Sachs, 1998).

Bloom ve Canning (2000: 1207) sağlığa dayalı büyüme hipotezini üretkenlik, eğitim, fiziksel sermaye yatırımı ve demografik temettü gibi çeşitli mekanizmalar üzerinden açıklamışlardır. Buna göre, sağlık harcamalarında meydana gelecek artışların bireylerin fiziksel ve zihinsel gelişimini olumlu yönde etkileyerek işgücü verimliliğini ve böylece üretkenliği artıracağı ifade edilmektedir. Bununla birlikte daha yüksek yaşam beklentisine sahip bireyler becerilerini geliştiren yatırımların faydalarını daha uzun süre boyunca elde etmeyi beklemektedir. Bu nedenle daha yüksek yaşam beklentisine sahip bireyler bilgi ve becerilerini geliştiren yatırımları yapmak için daha istekli olmaktadır. Ayrıca toplumun sağlık durumunun iyi olması okula devam etmeyi teşvik ederek daha yüksek gelir elde edilmesine yol açmaktadır. Benzer şekilde sağlık durumdaki iyileşme ortalama yaşam süresini artırarak bireylerin tasarruf eğilimini artırmaktadır. Artan tasarruf eğilimi fiziksel sermaye yatırımlarını teşvik ederek ekonomik büyümenin artmasına katkı sağlamaktadır. Son olarak demografik temettü kavramı ile nüfusun yaş yapısındaki değişmelerin çalışma çağındaki nüfusun oranında artışa yol açtığı 
ve böylece kişi başına düşen geliri önemli bir şekilde artıracağı ifade edilmektedir. $\mathrm{Bu}$ mekanizmalar aracılığıyla sağlık harcamaları ile ekonomik büyüme arasında pozitif bir ilişki olduğu ve bu ilişkinin yönünün sağlık harcamalarından ekonomik büyüme doğru olduğu raporlanmıştır.

Türkiye ekonomisinde sağlıkta dönüşüm programının uygulanmaya başlandığı 2003 yılından itibaren sağlık hizmetlerinin sunumu ve finansmanı noktasında önemli değişiklikler yapılmıştır. Bu kapsamda 9. Kalkınma Planı ile sağlık hizmetlerine erişimin artırılması, hizmet kalitesinin yükseltilmesi, Sağlık Bakanlığı'nın rolünün güçlendirilmesi gibi bir takım hedefler oluşturulmuştur. Bu doğrultuda, toplam sağlık harcamalarında önemli artışlar yaşanmıştır. Nitekim 2003-2019 döneminde kişi başına düşen sağlık harcamalarındaki ortalama artış hızı yaklaşık \%6 olarak gerçekleşmiştir. Bununla birlikte aynı dönemde kişi başına düşen gelirin artış hızı yaklaşık \%4 olarak gözlemlenmiştir. Değişkenlerde gözlemlenen bu birlikte artış eğilimi ve sağlık harcamalarındaki artışın ekonomik büyümenin üzerinde olduğu gerçeği, sağlık harcamalarının ekonomik büyüme üzerindeki etkisinin sorgulanması için gereklidir. Bu durum Türkiye ekonomisinde sağlığa dayalı büyüme hipotezinin geçerli olup olmadığı sorusunun cevaplanması gerekliliğini ortaya koymakta ve bu çalışmanın ana motivasyon kaynağını oluşturmaktadır. $\mathrm{Bu}$ doğrultuda, çalışmanın takip eden bölümünde ilgili literatüre yer verilecektir. Ardından çalışmanın veri seti ve yöntemi anlatılacaktır. Son kısımda ise ekonometrik analiz sonuçlarına yer verilecektir.

\section{Literatür}

Beşeri sermayenin ekonomik büyüme üzerindeki rolüne vurgu yapan Romer $(1986,1990)$ ve Lucas (1988)'ın öncü çalışmalarından sonra sosyal refah harcamalarının ekonomik büyüme üzerindeki rolüne yönelik birçok çalışma yapılmıştır. Dünya sağlık örgütü (2001) ve Avrupa komisyonu (2005) raporları, artan sağlık harcamalarının gelişmiş ve gelişmekte olan ülke grupları için ekonomik büyümeyi teşvik ettiğini ortaya koymaktadır. Ancak literatürde sosyal refah harcamalarından biri olan sağlık harcamalarını artırmanın ekonomik büyümeyi teşvik edip edemeyeceği konusunda bir fikir birliği yoktur. Bu nedenle söz konusu ilişki bağlamında tartışmalar iktisat yazınında yerini muhafaza etmektedir.

Ülke grupları bazında yapılan çalışmalardan Gerdtham ve Löthgren (2000), Yerdelen Tatoğlu (2011) ve Badri ve Badri (2016) OECD ülkelerinde sağlık harcamalarının ekonomik büyüme üzerindeki etkisinin pozitif olduğunu ortaya koymuşlardır. Buna karşılık Çetin ve Ecevit (2010), Hartwig (2010) ise OECD ülkelerinde sağlık harcamaları ile ekonomik büyüme arasında bir ilişkinin olmadığı sonucuna ulaşmışlardır. Benzer şekilde sağlık harcamalarının 
ekonomik büyüme üzerinde etkili olmadığını raporlayan Tufaner vd. (2020) kısa dönemde ekonomik büyümenin sağlık harcamalarını artırdığını tespit etmiştir. Brempong ve Wilson (2004), Gyimah-Brempong ve Wilson (2004) OECD ülkeleri ve Safraltı Afrika ülkelerinde Piabuo ve Tieguhong (2017) ise Orta Afrika Ekonomik ve Parasal Birliğine bağlı ülkeler ile 5 diğer Afrika ülkesinde sağlık harcamalarının ekonomik büyümeyi pozitif etkilediğini tespit etmişlerdir. Buna karşıllk, Eggoh vd. (2015) 49 Afrika ülkesinde eğitim ve sağlık harcamalarının ekonomik büyümeyi negatif etkilediği sonucunu raporlamışlardır. Sosyal refah harcamalarının ekonomik büyümeyi negatif yönde etkilemesini verimsizlik, yatırımların yetersizliği ve yolsuzluk kavramları ile açıklamışlardır. Naidu ve Chand (2013) Pasifik ada ülkelerinde sağlık harcamalarının ekonomik büyüme üzerindeki etkisinin güçlü olduğunu ve ele alınan ülkelerde yüksek büyüme oranlarına ulaşmak için sağlık sektörüne yönelik harcamaların artırılması gerektiğini ortaya koymuşlardır. Yıldız ve Yıldız (2018) 47 Avrupa ve Merkez Asya ülkesinde kişi başına düşen sağlık harcamalarının ekonomik büyümeyi pozitif yönde etkilediğini raporlamışlardır. Yang (2020) 21 gelişmekte olan ülkede sağlık harcamaları ile ekonomik büyüme arasındaki ilişkinin farklı beşeri sermaye seviyelerinde farklı etkilere sahip olduğunu ortaya koymuşlardır. Beşeri sermayenin düşük olması durumunda söz konusu değişkenler arasındaki ilişkinin negatif, yüksek olduğu durumda ise pozitif etkisinin arttığını tespit etmiştir.

Ülke bazında yapılan çalışmalardan Esteve vd. (2007) İspanya ekonomisinde, Boussalam vd. (2014) Cezayir ekonomisinde sağlık harcamaları ile ekonomik büyüme arasında uzun dönemli bir ilişki olduğunu ortaya koymuşlardır. Benzer şekilde Akram (2008) Pakistan ekonomisinde sağlık göstergelerinin uzun dönemde ekonomik büyümeyi pozitif yönde etkilediğini tespit etmiştir. Bunun aksine Ghorbel ve Kalai (2016) Tunus’ta uzun vadede beşeri sermayenin ekonomik büyüme üzerinde önemli etkileri olduğunu ancak sağlık harcamaları ile ekonomik büyüme arasında negatif bir ilişki olduğunu raporlamışlardır. Türkiye ekonomisini ele alan çalışmalardan Kıymaz vd. (2006), Sülkü ve Caner (2011) sağlık harcamalarının ekonomik büyüme üzerinde pozitif bir etkiye sahip olduğunu ortaya koymuşlardır. Tıraşoğlu ve Yıldırım (2012), Akar (2014), Erçelik (2018), Kızıl ve Ceylan (2018) sağlık harcamaları ile ekonomik büyüme arasında uzun dönemli pozitif bir ilişki olduğunu tespit etmişlerdir. Atılgan (2015) ise sağlık harcamaları ile ekonomik büyüme arasındaki pozitif ilişkinin hem kısa dönemde hem de uzun dönemde geçerli olduğunu ortaya koymuşlardır. Bu çalışmaların aksine Kar ve Taban (2003), Yumuşak ve Yıldırım (2009), Cömertler vd. (2015) incelenen ilişkinin negatif yönlü olduğunu raporlamışlardır. 


\section{Veri ve Yöntem}

$\mathrm{Bu}$ çalışmada Türkiye ekonomisinde sağlığa dayalı büyüme hipotezinin geçerliliği araştırılmıştır. Bu amaç doğrultusunda, 1990-2019 dönemleri arası yıllık veriler kullanılmıştır. Çalışmada ekonomik büyümeyi temsilen kişi başına düşen gelir değişkeni kullanılmıştır. Çalışmanın ekonometrik modeli ekonomik büyümeyi sağlık harcamaları, yükseköğretim brüt okullaşma oranı, doğrudan yabancı yatırımlar ve hanehalkı nihai tüketim harcamaları değişkenleriyle açıklayacak şekilde kurulmuştur. Çalışmada kullanılan değişkenler ve değişkenlerin veri kaynakları Tablo 1'de sunulmuştur. Kişi başına düşen gelir, kişi başına düşen sağlık harcamaları ve doğrudan yabancı yatırımlara ilişkin veriler Dünya Bankası'ndan, yükseköğretim brüt okullaşma oranına ilişkin veriler TÜİK' ten, hanehalkı nihai tüketim harcamalarına ilişkin veriler ise OECD veri tabanından elde edilmiştir. Analizde kişi başına düşen gelir, kişi başına düşen sağlık harcamaları, doğrudan yabancı yatırımlar ve hanehalkı nihai tüketim harcamaları değişkenleri logaritmik formda modele dahil edilmiştir.

Tablo 1. Değişkenlerin Tanımlanması

\begin{tabular}{|c|c|c|}
\hline Değişken & Sembol & Veri Kaynağı \\
\hline Kişi Başına Düşen Gelir (ABD Doları) & KBDG & Dünya Bankas1 \\
\hline Kişi Başına Düşen Sağlık Harcamaları (ABD Doları) & KBDSH & Dünya Bankas1 \\
\hline Yüksekögretim Brüt Okullaşma Oranı (\%) & YOK & TUİK \\
\hline Doğrudan Yabancı Yatırımlar (ABD Doları) & DYY & Dünya Bankas1 \\
\hline Hanehalkı Nihai Tüketim Harcamaları (ABD doları) & HTH & OECD \\
\hline
\end{tabular}

Çalışmada değişkenler arasındaki eş bütünleşme ilişkisinin tespit edilmesinde ARDL sınır testi yaklaşımı kullanılmıştır. ARDL sınır testi yaklaşımı Pesaran vd. (2001) tarafından geliştirilmiştir ve geleneksel eş bütünleşme testlerine göre (Engle-Granger, 1987; Johansen, 1988; Johansen-Juselius, 1990) bir takım avantajları bulunmaktadır. Bu avantajlardan ilki, eşbütünleşme ilişkisinin sınanmasında değişkenlerin aynı dereceden bütünleşik olma zorunluluğu bulunmaması ve dolayısıyla farklı derecelerden durağan seriler ile eşbütünleşme analizinin gerçekleştirilebilir olmasıdır. ARDL sınır testi yaklaşımının bir diğer avantajı, geleneksel eşbütünleşme testlerinin çok değişkenli modellerdeki etkinlik sorununu ortadan kaldırmasidır (Pesaran vd. 2001: 289-290). Kisıtsız hata düzeltme modeli kullanılan ARDL sınır testi yaklaşımının istatistiksel olarak daha iyi özelliklere sahip olması ve küçük örneklemlerde daha güvenilir sonuçlar elde edilmesine olanak sağlaması, söz konusu yaklaşımın avantajlarından bir diğeri olarak ifade edilebilir (Narayan ve Narayan, 2005: 429).

Üç aşamada tahmin edilen ARDL modelinde ilk olarak değişkenler arasında eşbütünleşme ilişkisi olup olmadığı araştırılmakta ve bu amaçla (1) numaralı denklemde yer alan Kısıtsız Hata Düzeltme Modeli (UECM) tahmin edilmektedir. İkinci olarak değişkenler arasında eşbütünleşme ilişkisi tespit edilirse, uzun dönemli bir ilişkinin olup olmadığı araştırılmaktadır. 
$\mathrm{Bu}$ amaçla (2) numaralı denklemde yer alan model tahmin edilmektedir. Üçüncü olarak değişkenler arasındaki kısa dönemli ilişkilerin araştırılması için (3) numaralı denklemde yer alan hata düzeltme modeli tahmin edilmektedir.

$$
\begin{aligned}
& \Delta K B D G_{t}=\alpha_{0}+\sum_{i=1}^{m} \alpha_{1} \Delta K B D G_{(t-i)}+\sum_{i=0}^{m} \alpha_{2} \Delta K B D S H_{(t-i)}+\sum_{i=0}^{m} \alpha_{3} \Delta Y O K_{(t-i)}+\sum_{i=0}^{m} \alpha_{4} \Delta D Y Y_{(t-i)} \\
& +\sum_{i=0}^{m} \alpha_{5} \Delta H T H_{(t-i)}+\alpha_{6} K B D G_{t-1}+\alpha_{7} K B D S H_{t-1}+\alpha_{8} Y O K_{t-1}+\alpha_{9} D Y Y_{t-1}+\alpha_{10} H T H_{t-1}+\varepsilon_{t} \\
& K B D G_{t}=\beta_{0}+\sum_{i=1}^{p} \beta_{1 i} K B D G_{(t-i)}+\sum_{i=0}^{q} \beta_{2 i} K B D S H_{(t-i)}+\sum_{i=0}^{r} \beta_{3 i} Y O K_{(t-i)}+\sum_{i=0}^{s} \beta_{4 i} D Y Y_{(t-i)} \\
& +\sum_{i=0}^{v} \beta_{5 i} H T H_{(t-i)}+e_{t} \\
& \Delta K B D G_{t}=\beta_{0}+\sum_{i=1}^{p} \beta_{1 i} \Delta K B D G_{(t-i)}+\sum_{i=0}^{q} \beta_{2 i} \Delta K B D S H_{(t-i)}+\sum_{i=0}^{r} \beta_{3 i} \Delta Y O K_{(t-i)} \\
& +\sum_{i=0}^{s} \beta_{4 i} \Delta D Y Y_{(t-i)}+\sum_{i=0}^{v} \beta_{5 i} \Delta H T H_{(t-i)}+\beta_{6} E C T_{(t-i)}+e_{t}
\end{aligned}
$$

\section{Ampirik Bulgular}

Zaman serisi analizlerinin ilk aşamasında modele dahil edilen değişkenlerin durağanlıkları

\begin{tabular}{|c|c|c|c|c|}
\hline \multicolumn{5}{|c|}{ ADF Birim Kök Testi Sonuçları } \\
\hline \multirow[t]{2}{*}{ Değişkenler } & \multicolumn{2}{|c|}{ (Düzey) } & \multicolumn{2}{|c|}{ (Birinci Fark) } \\
\hline & Sabit & Sabit+Trend & Sabit & Sabit+Trend \\
\hline LnKBDG & $\begin{array}{l}-1.1138 \\
(0.6965)\end{array}$ & $\begin{array}{c}-1.3386 \\
(0.8574)\end{array}$ & $\begin{array}{l}-5.6002 \\
(0.0001)\end{array}$ & $\begin{array}{c}-5.6335 \\
(0.0005)\end{array}$ \\
\hline LnKBDSH & $\begin{array}{l}-1.3562 \\
(0.5894)\end{array}$ & $\begin{array}{l}-1.0718 \\
(0.9168)\end{array}$ & $\begin{array}{l}-3.1902 \\
(0.0317)\end{array}$ & $\begin{array}{c}-5.9059 \\
(0.004)\end{array}$ \\
\hline YOK & $\begin{array}{c}2.3770 \\
(0.9999)\end{array}$ & $\begin{array}{l}-0.8433 \\
(0.9493) \\
\end{array}$ & $\begin{array}{l}-3.5098 \\
(0.0152) \\
\end{array}$ & $\begin{array}{l}-4.1455 \\
(0.0150) \\
\end{array}$ \\
\hline LnDYY & $\begin{array}{l}-1.2242 \\
(0.6500) \\
\end{array}$ & $\begin{array}{l}-1.7446 \\
(0.7049) \\
\end{array}$ & $\begin{array}{l}-5.3362 \\
(0.0002) \\
\end{array}$ & $\begin{array}{l}-5.2727 \\
(0.0011) \\
\end{array}$ \\
\hline LnHTH & $\begin{array}{l}-0.1853 \\
(0.9298) \\
\end{array}$ & $\begin{array}{l}-1.9327 \\
(0.6119) \\
\end{array}$ & $\begin{array}{l}-5.4791 \\
(0.0001) \\
\end{array}$ & $\begin{array}{l}-5.3647 \\
(0.0009)\end{array}$ \\
\hline \multicolumn{5}{|c|}{ PP Birim Kök Testi Sonuçları } \\
\hline \multirow[t]{2}{*}{ Değişkenler } & \multicolumn{2}{|c|}{ (Düzey) } & \multicolumn{2}{|c|}{ (Birinci Fark) } \\
\hline & Sabit & Sabit+Trend & Sabit & Sabit+Trend \\
\hline LnKBDG & $\begin{array}{l}-1.1012 \\
(0.7015) \\
\end{array}$ & $\begin{array}{c}-1.4723 \\
(0.8160) \\
\end{array}$ & $\begin{array}{l}-5.6002 \\
(0.0001) \\
\end{array}$ & $\begin{array}{c}-5.6335 \\
(0.0005) \\
\end{array}$ \\
\hline LnKBDSH & $\begin{array}{l}-1.3562 \\
(0.5894) \\
\end{array}$ & $\begin{array}{l}-1.2410 \\
(0.8824) \\
\end{array}$ & $\begin{array}{l}-4.1762 \\
(0.0031) \\
\end{array}$ & $\begin{array}{l}-4.1782 \\
(0.0139) \\
\end{array}$ \\
\hline YOK & $\begin{array}{c}2.1948 \\
(0.9999)\end{array}$ & $\begin{array}{l}-0.8890 \\
(0.9439)\end{array}$ & $\begin{array}{l}-3.5038 \\
(0.0154)\end{array}$ & $\begin{array}{l}-4.1696 \\
(0.0142)\end{array}$ \\
\hline LnDYY & $\begin{array}{l}-1.1874 \\
(0.6660)\end{array}$ & $\begin{array}{l}-1.7446 \\
(0.7049)\end{array}$ & $\begin{array}{l}-5.3705 \\
(0.0001)\end{array}$ & $\begin{array}{l}-5.3335 \\
(0.0009)\end{array}$ \\
\hline
\end{tabular}
sınanmaktadır. Bu doğrultuda değişkenlerin durağanlık düzeyleri literatürde en sık kullanılan ADF Augmented Dickey Fuller (ADF) ve Philips-Peron (PP) birim kök testleri ile sınanmıştır. Birim kök testi sonuçları Tablo 2'de sunulmuştur. Birim kök testi sonuçlarına göre, modele dahil edilen tüm değişkenler, sabit ve sabit+trendli model için I(1) olarak tespit edilmiştir.

Tablo 2. Birim Kök Testi Sonuçları 


\begin{tabular}{|c|c|c|c|c|}
\hline LnHTH & -0.1738 & -1.9475 & -5.4791 & -5.3647 \\
& $(0.9313)$ & $(0.6043)$ & $(0.0001)$ & $(0.0009)$ \\
\hline
\end{tabular}

Not: Parantez içindeki değerler prob değerlerini göstermektedir.

Serilerin durağan olup olmadıklarının birim kök testi ile sınanmasının ardından Eşitlik (1)'de gösterilen kısıtsız hata düzeltme modeli tahmin edilmiştir. Modelin tahmin aşamasına geçmeden önce ilk olarak optimal gecikme uzunluğu tespit edilmiştir. Şekil 1'de optimal gecikme uzunluğunun tespit edilmesi için değerlendirilen en iyi 20 model görülmektedir. Model için uygun gecikme uzunluğunun belirlenmesinde Akaike Bilgi Kriteri (AIC) kullanılmıştır. Bilgi kriterinin minimum olduğu ve otokorelasyon sorunu içermeyen model ARDL $(4,4,4,4,3)$ şeklindedir.

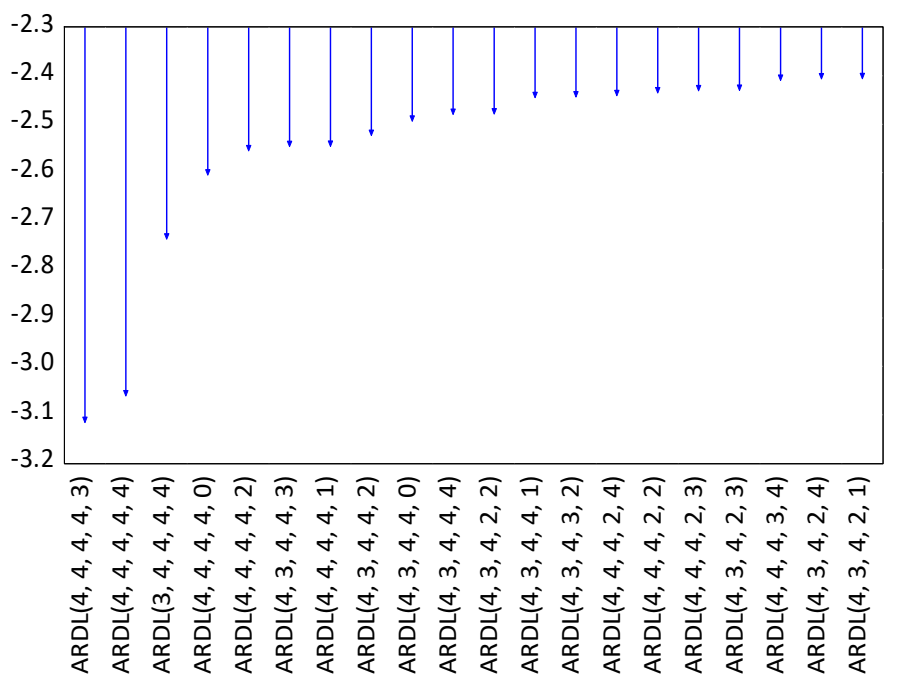

Şekil 1. Modele İlişkin Optimal Gecikme Uzunluğunun Seçildiği En İyi 20 Model

Model için uygun gecikme uzunluğunun tespitinin ardından değişkenler arasındaki eş bütünleşme ilişkisi sınır testi yaklaşımı ile değerlendirilmiştir. Bu doğrultuda, (1) numaralı eşitlikte yer alan UECM $(4,4,4,4,3)$ gecikme uzunluklarında tahmin edilmiştir. Tablo 3 'te sınır testi sonuçları sunulmuştur. Hesaplanan F istatistik değeri (23.04) \%1 anlamlılık düzeyinde üst kritik değerin (4.44) üzerindedir. Söz konusu değerlendirmeden hareketle, değişkenler arasında eşbütünleşme ilişkinin varlığı doğrulanabilir.

Tablo 3. Sınır Testi Sonuçları

\begin{tabular}{|c|c|c|c|c|}
\hline $\mathbf{k}$ & F İstatistik Değeri & \multicolumn{3}{|c|}{ Kritik Tablo Değeri } \\
\hline \multirow{2}{*}{4} & \multirow{2}{*}{23.04600} & & Alt Sınır & Üst Sınır \\
\cline { 3 - 5 } & & $\% 1$ & 3.07 & 4.44 \\
\hline
\end{tabular}

Not: Kritik değerler Pesaran vd. (2001)'den alınmıştır.

Değişkenler arasında eşbütünleşme ilişkisi olduğu tespit edildikten sonra, (2) numaralı denklem tahmin edilmiştir. ARDL $(4,4,4,4,3)$ modeline ilişkin tahmin sonuçları, tanısal denetim sonuçları ve uzun dönem katsayıları Tablo 4'te sunulmuştur. Tanısal denetim sonuçları 
doğrultusunda modelde otokorelasyon (Breusch-Godfrey testi), model kurma hatası (RamseyReset testi) ve değișen varyans (Breusch-Pagan-Godfrey testi) sorunu bulunmadığı ifade edilebilir. Bununla birlikte hata terimlerinin normal dağıldığı (Jarque-Bera Normallik testi) sonucuna ulaşılmaktadır. ARDL $(4,4,4,4,3)$ modelinden elde edilen uzun dönem katsayılarına göre, kişi başına düşen sağlık harcamaları, doğrudan yabancı yatırımlar ve hanehalkı nihai tüketim harcamaları kişi başına düşen geliri artırmaktadır. Bu bulgulara ilaveten yükseköğretim brüt okullaşma oranının kişi başına düşen gelir üzerinde negatif etkide bulunduğu sonucuna ulaşılmıştır. Elde edilen sonuçlar, istatistiki olarak anlamlıdır. Sonuçlar iktisadi teori bağlamında ele alındığında yükseköğretim brüt okullaşmanın ekonomik büyüme üzerindeki negatif etkisinin iktisadi teori ile uyumlu olmadığı ifade edilebilir. Çünkü içsel büyüme teorilerinde, beşeri sermayenin ekonomik büyüme sürecindeki önemine vurgu yapılmakta ve sağlık ile beraber eğitimin bu süreci desteklediği ifade edilmektedir. Ancak çalışma bulguları, Türkiye ekonomisinde yükseköğretim brüt okullaşma oranının ekonomik büyüme üzerinde pozitif bir dışsallığa sahip olmadığını ortaya koymaktadır. Doğrudan yabancı yatırımların ekonomik büyüme üzerindeki pozitif etkisinin iktisadi teori ile uyumlu olduğu ifade edilebilir. Doğrudan yabancı yatırımların, bilgi-teknoloji transferinin yanı sıra işletmelerin rekabetçi davranışlarının artırılmasında ve beşeri sermaye birikiminin artırılmasında önemli avantajlar sağladığı bilinmektedir. Bu durum ekonomik büyüme sürecine olumlu katkı sağlamaktadır. Hanehalkı nihai tüketim harcamalarının ekonomik büyümeyi artırıcı etkisinin de iktisadi teori ile örtüştügü ifade edilebilir. Söz konusu bulgu, Türkiye ekonomisinde son dönemlerde karşılaşılan talep yönlü büyümeyi destekler niteliktedir.

Tablo 4. ARDL $(4,4,4,4,3)$ Modelinin Tahmin Sonuçları

\begin{tabular}{|c|c|c|c|}
\hline Bă̆ımlı Değişken: LnKBDG & Katsayı & t istatistiği & Prob \\
\hline Değişkenler & 0.0394 & 0.2492 & 0.8103 \\
\hline Ln(KBDG(-1)) & 0.1235 & 0.8124 & 0.4433 \\
\hline Ln(KBDG(-2)) & -0.7929 & -4.8952 & 0.0018 \\
\hline Ln(KBDG(-3)) & -0.5712 & -4.3334 & 0.0034 \\
\hline Ln(KBDG(-4)) & 1.0466 & 2.4435 & 0.0445 \\
\hline Ln(KBDSH) & -1.6599 & -3.1711 & 0.0157 \\
\hline $\operatorname{Ln}($ KBDSH(-1)) & 1.7501 & 3.9672 & 0.0054 \\
\hline $\operatorname{Ln}($ KBDSH(-2)) & -1.3664 & -3.5068 & 0.0099 \\
\hline $\operatorname{Ln}($ KBDSH(-4)) & 0.6371 & 2.4957 & 0.0412 \\
\hline YOK & 0.0042 & 0.7434 & 0.4814 \\
\hline YOK(-1) & 0.0098 & 1.3587 & 0.2164 \\
\hline YOK(-2) & 0.0139 & 1.5654 & 0.1614 \\
\hline YOK(-3) & -0.0153 & -1.5855 & 0.1569 \\
\hline YOK(-4) & -0.0261 & 3.5449 & 0.0094 \\
\hline $\operatorname{Ln}(\mathrm{DYY})$ & -0.0745 & -1.5283 & 0.1703 \\
\hline $\operatorname{Ln}(\mathrm{DYY}(-1))$ & 0.1399 & 2.4835 & 0.0420 \\
\hline $\operatorname{Ln}(\mathrm{DYY}(-2))$ & 0.3114 & 5.4141 & 0.0010 \\
\hline $\operatorname{Ln}(\mathrm{DYY}(-3))$ & -0.0386 & -0.8932 & 0.4014 \\
\hline
\end{tabular}




\begin{tabular}{|c|c|c|c|}
\hline Ln(HTH) & 0.3752 & 0.4889 & 0.6398 \\
\hline $\operatorname{Ln}(\mathrm{HTH}(-1))$ & 0.4173 & 0.7639 & 0.4698 \\
\hline $\operatorname{Ln}(\mathrm{HTH}(-2))$ & -1.0468 & -1.9106 & 0.0977 \\
\hline $\operatorname{Ln}(\mathrm{HTH}(-3))$ & 1.3024 & 2.4728 & 0.0427 \\
\hline \multicolumn{4}{|c|}{ Uzun Dönem Katsayıları } \\
\hline LnKBDSH & 0.1851 & 5.2706 & 0.0012 \\
\hline YOK & -0.0061 & -6.3547 & 0.0004 \\
\hline LnDYY & 0.2168 & 5.2213 & 0.0012 \\
\hline LnHTH & 0.4761 & 2.8826 & 0.0236 \\
\hline \multirow{2}{*}{\multicolumn{4}{|c|}{ Tanısal Denetim Sonuçları }} \\
\hline & & & \\
\hline$\overline{\boldsymbol{R}}^{2}$ & \multicolumn{3}{|c|}{0.94} \\
\hline$\chi_{N O R M}^{2}$ & \multicolumn{3}{|c|}{$0.8624(0.6496)$} \\
\hline$\chi_{\mathrm{BG}}^{2}$ & \multicolumn{3}{|c|}{$1.2589(0.3607)$} \\
\hline$\chi_{B P G}^{2}$ & \multicolumn{3}{|c|}{$0.6356(0.8001)$} \\
\hline$\chi_{R A M S E Y}^{2}$ & \multicolumn{3}{|c|}{$4.7259(0.0727)$} \\
\hline
\end{tabular}

Not: Parantez içindeki değerler prob değerlerini göstermektedir. $\chi_{N O R M}^{2}, \chi_{\mathrm{BG}}^{2}, \chi_{B P G}^{2}, \chi_{R A M S E Y}^{2}$ sırasıyla normallik, otokorelasyon, değişen varyans, model kurma hatası test istatistikleridir.

Değişkenler arasındaki uzun dönemli ilişkilerin tespitinin ardından kısa dönemli ilişkiler hata düzeltme modeli yardımıyla incelenmiştir. Hata düzeltme modeli (3) numaralı denklem yardımıyla tahmin edilmiştir. Tahmin sonuçları Tablo 5'te yer almaktadır. Elde edilen sonuçlara göre, kişi başına düşen gelire ilişkin gecikmeli değerler kısa dönemde kendi üzerinde pozitif bir etkiye sahiptir. Kişi başına düşen sağlı harcamalarının ilk yılda kişi başına gelir üzerinde ortaya çıkardığı etkinin pozitif olduğu görülmektedir. Elde edilen bu sonuçlar, istatistiki olarak anlamlıdır. Bununla birlikte yükseköğretim brüt okullaşma oranının da kişi başına düşen gelir üzerindeki etkisi pozitif olarak raporlanmıştır. Ancak istatistiki olarak bir değerlendirme yapıldığında ilk yıldaki söz konusu pozitif etkinin anlamsız olduğu tespit edilmiştir. Doğrudan yabancı yatırımların kısa dönemde kişi başına düşen gelir üzerinde negatif bir etkiye sahip olduğu tahmin edilmiştir. İstatistiki bir değerlendirme yapıldığında, elde edilen bu sonucun anlamlı olduğu görülmektedir. Kişi başına düşen gelir üzerinde hanehalkı nihai tüketim harcamalarının ilk dönemdeki etkisi pozitiftir, ancak elde edilen bu sonuç istatistiki olarak anlamsızdır. Takip eden dönemlerde etkinin negatife döndüğ̈ görülmekle birlikte, ikinci yıl için elde edilen bu sonucun istatistiki olarak anlamsız olduğu sonucuna ulaşılmıştır. Bununla birlikte hata düzeltme katsayısı negatif ve istatistiksel olarak anlamlıdır. Hata düzeltme katsayısının -2.20 olarak bulunması, dengeden herhangi bir sapma oluşturacak şokun uzun dönem dengesinden uzaklaşan bir süreç ortaya çıkardığını göstermektedir.

Tablo 5. ARDL (4,4,4,4,3) Modeline İlişkin Hata Düzeltme Modeli Tahmin Sonuçları

\begin{tabular}{|c|c|c|c|}
\hline Bağımlı Değişken: LnKBDG & t istatistĭ̆ & Prob \\
\hline Değişkenler & Katsayı & 9.7569 & 0.0000 \\
\hline $\mathrm{D}($ LnKBDG(-1)) & 1.2406 & 10.8962 & 0.0000 \\
\hline $\mathrm{D}($ LnKBDG(-2)) & 1.3641 & 6.3689 & 0.0004 \\
\hline $\mathrm{D}($ LnKBDG(-3)) & 0.5712 & 5.5380 & 0.0009 \\
\hline $\mathrm{D}($ LnKBDSH) & 1.0466 & -4.7130 & 0.0022 \\
\hline
\end{tabular}




\begin{tabular}{|c|c|c|c|}
\hline \multicolumn{4}{|l|}{ Bağımlı Değişken: LnKBDG } \\
\hline Değişkenler & Katsayı & $t$ istatistiği & Prob \\
\hline $\mathrm{D}(\operatorname{LnKBDSH}(-2))$ & 0.7293 & 4.4689 & 0.0029 \\
\hline $\mathrm{D}(\operatorname{LnKBDSH}(-3))$ & -0.6371 & -6.0023 & 0.0005 \\
\hline $\mathrm{D}(\mathrm{YOK})$ & 0.0042 & 1.2738 & 0.2435 \\
\hline $\mathrm{D}(\mathrm{YOK}(-1))$ & 0.0275 & 7.6250 & 0.0001 \\
\hline $\mathrm{D}(\mathrm{YOK}(-2))$ & 0.0414 & 8.6095 & 0.0001 \\
\hline $\mathrm{D}(\mathrm{YOK}(-3))$ & 0.0261 & 6.2857 & 0.0004 \\
\hline $\mathrm{D}(\operatorname{LnDYY})$ & -0.0745 & -3.0026 & 0.0199 \\
\hline $\mathrm{D}(\operatorname{LnDYY}(-1))$ & -0.4119 & -11.0549 & 0.0000 \\
\hline $\mathrm{D}(\operatorname{LnDYY}(-2))$ & -0.1004 & -3.6319 & 0.0084 \\
\hline $\mathrm{D}(\operatorname{LnDYY}(-3))$ & -0.1391 & -6.9294 & 0.0002 \\
\hline $\mathrm{D}(\mathrm{LnHTH})$ & 0.3752 & 1.5614 & 0.1624 \\
\hline $\mathrm{D}(\mathrm{LnHTH}(-1))$ & -0.2555 & -0.9048 & 0.3956 \\
\hline $\mathrm{D}(\mathrm{LnHTH}(-2))$ & -1.3024 & -4.9660 & 0.0016 \\
\hline ECT $(-1)$ & -2.2011 & -13.4564 & 0.0000 \\
\hline
\end{tabular}

Hata düzeltme modelinin tahminin ardından, parametrelerin kararlığını araştırmak amacıyla CUSUM ve CUSUMSQ testleri yapılmıştır. Test sonuçları Şekil 2'de yer almaktadır. Test sonuçlarına göre, artıklar güven sınırı içerisinde kaldığından parametrelerin kararlı olduğu ifade edilebilir. Bu doğrultuda modelde yapısal kırılmanın olmadığg görülmektedir.

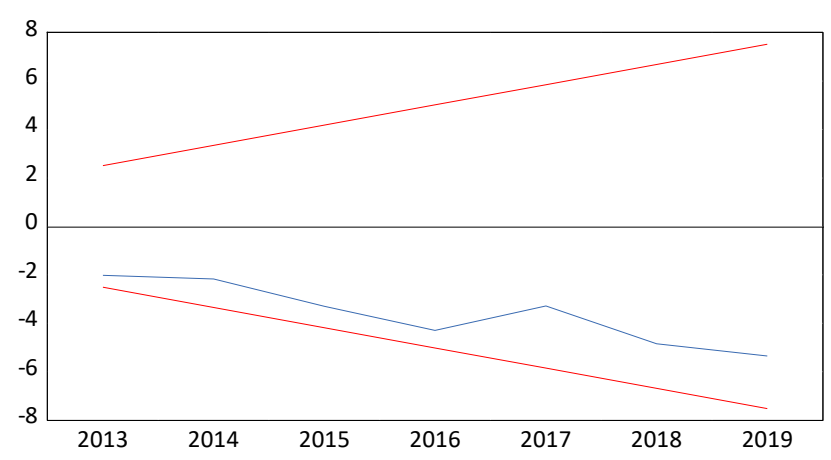

_ CUSUM — $5 \%$ Significance

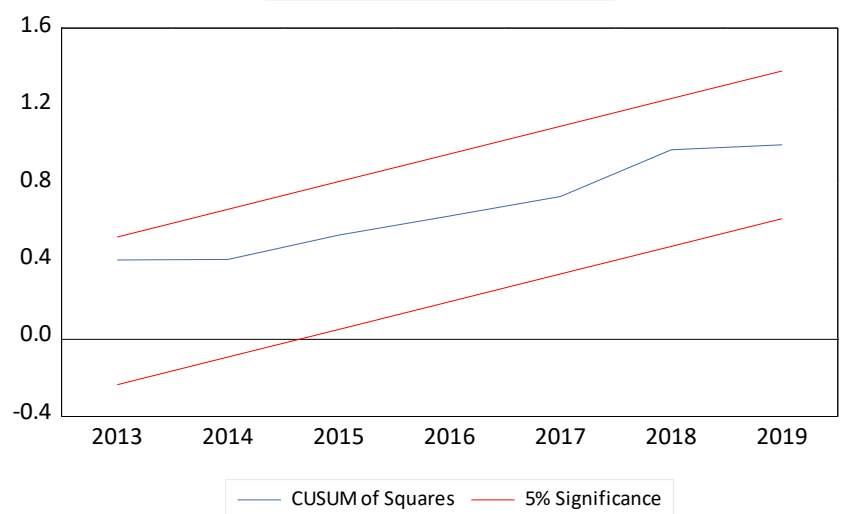

Şekil 2. Modele İlişkin CUSUM ve CUSUMSQ Testi Sonuçları

\section{Sonuç}

Çalışmada Türkiye ekonomisinde sağlığa dayalı büyüme hipotezinin geçerliliği 1990-2019 dönemi için araştırılmıştır. Analiz yöntemi olarak ARDL sınır testi yaklaşımı kullanılmış ve analizler yıllık verilerle gerçekleştirilmiştir. Çalışmanın ekonometrik modelinde kişi başına 
düşen gelir bağımlı değişken, kişi başına düşen sağlı harcamaları, yükseköğretim brüt okullaşma oranı, doğrudan yabancı yatırımlar ve hanehalkı nihai tüketim harcamaları bağımsız değişken olarak kullanılmıştır.

Çalışmadan elde edilen ampirik bulgulara göre, uzun dönemde kişi başına düşen sağlık harcamaları, doğrudan yabancı yatırımlar ve hanehalkı nihai tüketim harcamaları kişi başına düşen geliri pozitif yönde etkilemektedir. Bununla birlikte yükseköğretim brüt okullaşma oranının kişi başına düşen gelir üzerindeki etkisi negatif olarak tespit edilmiştir. Kısa dönemde, kişi başına düşen sağlık harcamaları, yükseköğretim brüt okullaşma oranı ve hanehalkı nihai tüketim harcamaları kişi başına düşen gelir üzerinde pozitif bir etkiye sahiptir. Aynı zamanda, doğrudan yabancı yatırımların kişi başına düşen gelir üzerinde negatif bir etkiye sahip olduğu sonucuna ulaşılmıştır.

Çalışma bulguları, yükseköğretim brüt okullaşma oranının ekonomik büyüme üzerindeki etkisinin uzun dönemde negatif olduğunu ortaya koymaktadır. Söz konusu ampirik bulgu, Gregorio (1992), Glewwe ve Mai (2014) ve Eggoh vd. (2015)'nin çalışma bulguları ile örtüşmektedir. Elde edilen bu sonuç, yalnızca yükseköğretimin değil aynı zamanda yükseköğretim kalitesinin de ekonomik büyüme süreci üzerindeki önemine vurgu yapmaktadır. Bu bağlamda Türkiye ekonomisinde yükseköğretim okullaşma oranının artırılmasının yanı sıra yükseköğretimin niteliğini artıracak politikaların geliştirilmesinin hem ekonomik büyüme sürecine hem de beșeri sermayeye katkı sağlayacağı öngörülmektedir. Bu kapsamda akademik personel başına düşen öğrenci sayılarının azaltılması, üniversitelerin araştırma altyapılarının geliştirilmesi ve etkin kullanımının sağlanması, öğretim elemanlarının niteliğini ve motivasyonunun artırılması, yükseköğretimin iş gücü piyasası ile uyumlu hale getirilmesi sağlanabilir. Yükseköğretim brüt okullaşma oranının ekonomik büyüme üzerindeki söz konusu negatif etkisinin iktisadi teori ile örtüşmediği ifade edilebilir. Nitekim içsel büyüme teorileri, sağlık ile eğitimin ekonomik büyüme sürecindeki önemine vurgu yapmaktadır. Ayrıca çalışma bulguları, doğrudan yabancı yatırımların ve hanehalkı nihai tüketim harcamalarının ekonomik büyüme üzerine uzun dönemde pozitif bir etkiye sahip olduğunu ortaya koymaktadır. Doğrudan yabancı yatırımların ekonomik büyüme üzerine pozitif bir katkısının olduğunu ortaya koyan Köprücü (2016) ve Osei ve Kim (2020)'in çalışmalarının bulguları ile örtüşen bu ampirik sonucun aynı zamanda iktisadi teori ile de uyumlu olduğu ortaya konabilir. Nitekim doğrudan yabancı yatırımların ekonomilere birçok açıdan avantaj sağladığı bilinmektedir. Söz konusu avantajların en önemlilerinden biri bilgi ve teknoloji alanında olmaktadır. Bu bağlamda doğrudan yabancı yatırımın yapıldığı ekonomilerde önemli verimlilik artışları yaşanmakta ve üretim kapasitesi artmaktadır. Literatürde, hanehalkı nihai tüketim harcamaları ile ekonomik 
büyüme arasındaki ilişkiyi ampirik olarak sınayan az sayıda çalışma bulunmaktadır. Hanehalkı nihai tüketim harcamaları ile ekonomik büyüme ilişkisine dair ortaya konulan ampirik bulgunun Tapsin ve Venkatraja (2017), Sarı ve Dinç (2021)'in çalışmaları ile örtüştüğü ancak bununla birlikte Koyuncu ve Ünal (2020)'in çalışmasından bu yönüyle farklılaştı̆ğ ifade edilebilir. İktisadi teori bağlamında talep yönlü büyümeyi açılamaya yönelik geniş bir literatür bulunmakta ve talep yönlü büyüme iki farklı yaklaşım çerçevesinde ele alınmaktadır. İlk olarak, toplam talebin önemli bir bileşeni olan hanehalkı nihai tüketim harcamalarındaki bir artışın üretim faktörü artışına yol açtığı ve böylece doğal büyüme oranını artırdığı ifade edilmektedir. İkinci olarak, üretim faktörlerinin büyüme sürecindeki pozitif katkısı göz ardı edilerek talep artışının doğrudan ekonomik büyüme üzerinde etkili olduğu belirtilmektedir. Bu bağlamda, hanehalkı nihai tüketim harcamaları ile ekonomik büyüme arasındaki ilişkiye dair ortaya konan bu ampirik bulgunun, iktisadi teori bağlamında desteklendiği görülmektedir. Özellikle de 1980’lerden sonra neoliberal politikalar benimseyen ekonomilerde özel tüketim harcamalarının önemi giderek artmaktadır. $\mathrm{Bu}$ nedenle hanehalkı nihai tüketim harcamalarının ekonomik büyüme sürecine pozitif katkı sağlaması beklenmektedir.

Çalışma bulguları, konunun ana odak noktasını oluşturan sağlık harcamaları ile ekonomik büyüme arasındaki ilişkiye dair kanıtlar sunmaktadır. Çalışma bulgularından hareketle, Türkiye ekonomisinde sağlığa dayalı büyüme hipotezinin geçerli olduğu ifade edilebilir. Elde edilen bu sonuç, Tıraşoğlu ve Yıldırım (2012), Akar (2014), Atılgan (2015), Erçelik (2018), Kızıl ve Ceylan (2018)'ın çalışma bulguları ile örtüşmektedir. Türkiye'de sağlık sektörüne yönelik 2003 yılından bu yana bir dizi reformlar gerçekleştirilmiştir. Bu reformlarla, sağlık hizmetlerinin sunumu ve finansmanı noktasında önemli değişiklikler yapılmıştır. Bu reformlar, hem sağlık hizmeti arzını hem de sosyal sigorta kapsamının genişletilmesinden dolayı sağlık hizmeti talebini olumlu bir şekilde etkilemiştir. Bununla birlikte 2004 yılının başlangıcında hastanelerde performansa dayalı ödeme sistemine geçilmiştir. Bu sistemin sağlık hizmetlerinin sunumu noktasında niteliği destekleyici olduğu ifade edilebilir.

Bu doğrultuda, ekonomik büyüme sürecinde sağlık harcamalarının rolünün artırılması için sağlık sektörüne daha fazla kaynak ayrılması ve tahsis edilen kaynakların etkin bir şekilde kullanılması gerekmektedir. Sağlık harcamalarının daha etkin kullanılmasını sağlayacak politikaların uygulanması ortalama yaşam beklentisinin, eğitim düzeyinin, tasarruf eğiliminin ve işgücü verimliliğinin artmasına katkı sağlayacaktır. Dolayısıyla sağlık sektörüne yapılan harcamaların beşeri sermaye birikimini destekleyerek ekonomik büyümeyi teşvik edeceği öngörülmektedir. Buna ilaveten olumsuz sağlık koşullarının yoksulluk tuzağına yol açtığı gerçekliğinden hareketle, sağlık sektörüne yönelik politikaların etkinliğinin olumsuz sağlık 
koşullarının yol açtığg yoksulluk sorunun çözümüne katkı yapacağı değerlendirilmektedir. Bu bağlamda Türkiye ekonomisinde sürdürülebilir bir ekonomik büyüme sağlaması hususunda sağlık harcamalarının destekleyici rolünü ortaya koyan çalışma bulgularından ve konuyla ilgili iktisadi yazından hareketle, Türkiye'de sağlık harcamalarının artırılmasının insani ve ekonomik yönleriyle ayrı ayrı değerlendirilebilecek bir politika aracı olduğu sonucuna varılmıştır.

Gelecek çalışmalar, sağlığa dayalı büyüme hipotezini doğrusal olmayan modeller yardımıyla sınayarak, ilişkinin yönünün kişi başına düşen gelir veya kişi başına düşen sağlık harcamalarının herhangi bir eşik değeri ile değişip değişmediğini araştırabilir. Buna ilaveten kişi başına düşen sağlık harcamaları, beşeri sermaye faktörü ile ilişkilendirilerek büyüme ve büyümenin üretim faktörleri arasındaki dağılımı açıklanmaya çalışabilir. 


\section{KAYNAKÇA}

Akar, S. 2014. “Türkiye’de Sağlık Harcamaları, Sağlık Harcamalarının Nisbi Fiyatı ve Ekonomik Büyüme Arasındaki İlişskinin İncelenmesi.' Yönetim ve Ekonomi 21(1): 312-322.

Akram, N., Padda, I.H., \& Khan, M. 2008. "The Long Term Impact of Health on Economic Growth in Pakistan." Development Review 47(4): 487-500.

Atılgan, E. 2015. "The Health-Led Growth Hypothesis: An empirical evidence from Turkey", Proceedings of The IRES 21st, 25 Aralik, 2015/ Amsterdam-Hollanda.

Avrupa Komisyonu. 2005. The Contribution of Health to The Economy of The European Union. Luxembourg: Office for Official Publications of the European Communities.

Badri, A.K., \& Badri, S.K. 2016. "Health Spending and Economic Growth in Selected OECD Countries." American Journal of Clinical Neurology and Neurosurgery 2(1): 5-9.

Beraldo, S., \& Montolio, D.,Turati, G. 2009. "'Healthy, Educated and Wealthy: A Primer on The Impact of Public and Private Welfare Expenditures on Economic Growth.'” The Journal of Socio-Economic 38: 946-956.

Bloom, D.E., \& Canning, D. 2000. “'The Health and Wealth of Nations.' Science 287(5456): 1207-1209.

Bloom, D.E., \& Sachs, J.D. 1998. “Geography, Demography, and Economic Growth in Africa.” Brookings Papers on Economic Activity 2: 207-215.

Boussalem, F., Bossalem, Z., \& Taiba, A. 2014. “The Relationship Between Public Spending on Health and Economic Growth in Algeria: Teting For Co-Integration and Causality.' International Journal of Business and Management 2(3): 25-39.

Brempong, K.G., \& Wilson, M. 2004. "Health Human Capital and Economic Growth in Sub-Saharan African and Oecd Countries."' The Quarterly Review of Economics and Finance 44: 296-320.

Büyükakın, F., Bozkurt, H., \& Cengiz, V. 2009. “Türkiye'de Parasal Aktarımın Faiz Kanalının Granger Nedensellik Ve Toda Ve Yamamoto Yöntemleri İle Analizi.' Erciyes Üniversitesi İktisadi ve İdari Bilimler Fakülte Dergisi 33: 101-118.

Cole, M.A., \& Neumayer E. 2006. "The İmpact of Poor Health on Total Factor Productivity." Journal of Development Studies 42: 918-938.

Cömertler Şimşir, N., Çondur, F., Bölükbaş, M., \& Alataş, S. 2015. “Türkiye’de Sağlık ve Ekonomik Büyüme İlişkisi: ARDL Sınır Testi Yaklaşımı.'” Finans Politik \& Ekonomik Yorumlar 52(604): 43-54.

Çetin, M., \& Ecevit, E. 2010. “Sağlık Harcamalarının Ekonomik Büyüme Üzerine Etkisi: OECD Ülkeleri Üzerine Bir Panel Regresyon Analizi.’’ Doğuş Üniversitesi Dergisi 11(5):166-182.

Dünya Sağlık Örgütü. 2001. Macroeconomics and Health: Investing in Health for Economic Development. Geneva: Commission on Macroeconomics and Health, World Health Organization.

Eggoh, J., Houeninvo, H., \& Sossou, G.A. 2015. "Education, Health And Economic Growth İn African Countries." Journal of Economic Development 40(1): 93-111.

Elmi, Z. M., \& Sadeghi, S. 2012. 'Health Care Expenditures and Economic Growth in Developing Countries: Panel Co-Integration and Causality.' 'Middle-East Journal of Scientific Research 12(1): 88-91.

Erçelik, G. 2018. “The Relationship Between Health Expenditure and Economic Growth in Turkey From 1980 to 2015." Journal of Politics, Economy and Management 1(1): 1-8.

Esteve, V., \& Martinez-Zahonero, J. L. 2007. ' Testing the Long-Run Relationship Between Health Expenditures and GDP in The Presence of Structural Change: The Case of Spain.' Applied Economics Letters 14(4): 271-276.

Gerdtham, U.G., \& Löthgren, M. 2000. “'On Stationarity and Cointegration of İnternational Health Expenditure and GDP.'" Journal of Health Economics 19(4): 461-475.

Ghorbel, A., \& Kalai, M. 2016. "Health Expenditure, Human Capital and Economic Growth in Tunisia: An ARDL Bounds Testing Approach." Journal of Business Management and Economics 4(8): 36-45.

Glewwe, P., \& Mai, N. I. E. 2014. "The Contribution of Education to Economic Growth: A Review of The Evidence, with Special Attention and An Application to Sub-Saharan Africa.' World Development 59: 379-393.

Granger, C. W. 1969. "Investigating Causal Relations by Econometric Models and Crossspectral Methods" Econometrica 37(3): 424-438.

Gregorio, J. De. 1992. 'Economic Growth in Latin America.' Journal of Development Economics 39(1): 59-84.

Gyimah-Brempong, K., \& Wilson, M. 2004. "Health Human Capital and Economic Growth in Sub-Saharan African and OECD Countries.' The Quarterly Review of Economics and Finance 44(2): 296-320.

Hartwig, J. 2010. ' Is Health Capital Formation Good for Long-term Economic Growth?-Panel Granger-causality Evidence for OECD Countries.' Journal of Macroeconomics 32: 314-325.

Kar, M., \& Taban, S. 2003. "Kamu Harcama Çeşitlerinin Ekonomik Büyüme Üzerine Etkileri." Ankara Üniversitesi Siyasal Bilgiler Fakültesi Dergisi 58(3): 145-169.

Kaya, V., Çelik, A., \& Kutlu, M. 2020. 'PPersonal İ́ncome Distribution in Turkey: A Generalized Ordered Logit Analysis.' Economic Journal of Emerging Markets 12(2): 138-150. 
Kıymaz, H., Akbulut, Y., \& Demir, A. 2006. “Tests of Stationarity and Cointegration of Health Care Expenditure and Gross Domestic Product."' The European Journal of Health Economics 7(4): 285-289.

Kızıl, B.C., \& Ceylan, R. 2018. "Sağlık Harcamalarının Ekonomik Büyüme Üzerine Etkisi: Türkiye Örneği."' Journal of Yasar University 13(50): 197-209.

Koyuncu, C., \& Ünal, H. S. 2020. "The Link between GDP and Household Consumption Expenditures in the Longrun in Turkey: ARDL Analysis.' Balkan ve Near Eastern Journal of Social Sciences 6(1): 171-177.

Köprücü, Y. 2016. "Doğrudan yabancı yatırımların ekonomik büyüme üzerindeki etkisi: Türkiye örneği' International Conference on Eurasian Economies, 809-813.

Kutluay-Tutar, F., \& Ekici, M. 2020. “Ekonomik Büyümenin Lokomotifi Olan Sağlık Sektörü ve Türkiye Uygulamas1.' International Journal of Social, Humanities and Administrative Sciences, 6(30): 13351342.

Lucas, R.E. 1988. "On The Mechanics of Economic Development.' Journal of Monetary Economics 22(1): 3-42.

Maduka, A. C., Madichie, C. V., \& Ekesiobi, C. S. 2016. "Health Care Expenditure, Health Outcomes, and Economic Growth Nexus in Nigeria: A Toda-Yamamoto Causality Approach.' Journal of Economics and International Finance 2(1): 1-10.

Mushkin, S.J. 1962. "Health As an Investment'” Journal of Political Economy 70(5): 129-157.

Naidu, S., \& Chand, A. 2013. "Does Central Government Health Expenditure and Medical Technology Advancement Determine Economic Growth Rates in The Pacific İsland Countries?’’ Asia-Pacific Journal of Business Administration 5(3): 234-245.

Narayan, P. K., \& Narayan, S.2005. "Estimating Income and Price Elasticities of Imports for Fiji in A Cointegration Framework.' Economic Modelling 22 (3): 423-438.

Osei, M.J., \& Kim, J. 2020. 'FForeign Direct İnvestment and Economic Growth: Is More Financial Development Better?' Economic Modelling, 93: 154-161.

Pata, U.K. 2018. “Türkiye'de Enflasyon, Tasarruf ve Ekonomik Büyüme Arasındaki İlişkilerin Simetrik ve Asimetrik Nedensellik Testleri İle Analizi.’' Maliye Dergisi 174: 92-111.

Pesaran, M. H., Shin, Y., \& Smith, R. S. 2001. "Bound Testing Approaches To The Analysis of Level Relationships.' Journal of Applied Econometrics 16(3): 289-326.

Piabuo, S.M., \& Tieguhong, J.C. 2017. "Health Expenditure and Economic Growth-A Review The Literature and An Analysis between The Economic Community for Central African States (CEMAC) and Selected African Countries.' 'Health Economics Review 7(1): 23.

Romer, P. M. 1990. “'Endogenous Technological Change.’ The Journal of Political Economy 98(5): $71-101$.

Romer, P.M. 1986. “'Increasing Returns and Long-Run Growth.” Journal of Political Economy 94(5): 1002-1037.

Sarı, S., \& Dinç, M. 2021. "Tüketim Harcamalarının Ekonomik Büyüme Üzerindeki Etkisinin Fourier Yaklaşımı İle İncelenmesi: Türkiye Örneği."' Balkan ve Yakın Doğu Sosyal Bilimler Dergisi 7(4): 61-70.

Schultz, T. P. 1999. "'Health and schooling investments in Africa."' Journal of Economic Perspectives 13(3): 6788.

Sülkü, S. N., \& Caner, A. 2011. "Health Care Expenditures and Gross Domestic Product: The Turkish Case." The European Journal of Health Economics 12(1): 29-38.

Tapsin, G., \& Hepsag, A. 2014. “An Analysis of Household Consumption Expenditures in EA-18.” European Scientific Journal 10(16): 1-12.

Tıraşoğlu, M., \& Yıldırım, B. 2012. "Yapısal Kırılma Durumunda Sağlık Harcamaları Ve Ekonomik Büyüme İlișkisi: Türkiye Üzerine Bir Uygulama.”' Electronic Journal of Vocational Colleges 2(2):111-117.

Toda, Y.H., \& Yamamoto, T. 1995. “Statistical İnference in Vector Auto Regressions with Possibly İntegrated Process.' Journal of Econometrics 66, 225-250.

Tufaner, M.B., Dizge, F., \& Emir, Z. 2020. 'OEECD ülkelerinde sağlık harcamaları-ekonomik büyüme ilişkisi”, Internatıonal Conference on Eurasıan Economies, Eylül 2-4.

Yang, X. 2020. “'Health Expenditure, Human Capital, and Economic Growth: An Empirical Study of Developing Countries.' International Journal of Health Economics and Management 20:163-176.

Yerdelen Tatoğlu, F. 2011. "The Relationships Between Human Capital Investment and Economic Growth: A Panel Error Correction Model.', Journal of Economic and Social Research 13(1): 75-88.

Yıldız, B., \& Yıldız, G. 2018. "Sağlık Harcamalarının Ekonomik Büyüme Üzerindeki Etkisi: Avrupa ve Merkez Asya Ülkeleri Örneği.” Maliye Dergisi 174: 203-218.

Yumuşak, İ.G., \& Yıldırım, D. Ç. 2009. “'Sağlık Harcamaları İktisadi Büyüme İlişkisi Üzerine Ekonometrik Bir İnceleme.’ The Journal of Knowledge Economy \& Knowledge Management 4: 57-70. 